\title{
Analysis of adjustment of satellite precipitation for streamflow simulations
}

\author{
K. Tobin \& M. Bennett \\ Centre for Earth and Environmental Studies, \\ Texas A\&M International University, USA
}

\begin{abstract}
The lack of dense ground networks of meteorological stations in many parts of the developing world impedes accurate hydrological modelling. These are regions that could greatly benefit from satellite precipitation data. However, there are significant problems with satellite products in providing reasonable estimates of precipitation over land. Methods exist that can adjust satellite products (with ground gauge or radar data) providing more robust estimates of precipitation. However, high quality ground data may not exist within the pixel, typically $0.25^{\circ} \times 0.25^{\circ}$, to provide the necessary information to facilitate the adjustment of the satellite product. To address this problem this study will examine how streamflow performance, based on satellite products (TRMM 3B42 Real-time - TMPA-RT; CMORPH) adjusted with ground precipitation data, will vary over a range of spatial transfer distances $\left(0^{\circ}\right.$ to $\left.3.00^{\circ}\right)$. The spatial transfer distance is the mean distance that a rain gauge is located away from the centroid of the watershed. This study compares simulated (driven by adjusted satellite precipitation) and observed streamflow from six moderately large basins from the United States. These basins span a range of climatic conditions from dry (San Pedro Basin - Arizona; Cimmaron Basin - Oklahoma; Nueces Basin - South Texas; middle Rio Grande Basin - Texas and northern Mexico) to humid (Alapaha Basin - Georgia; Upper Tar Basin - North Carolina). This study is unique because it quantities how far spatially transferred precipitation data can be potentially applied to support hydrologic modelling, which is knowledge that can be applied to poorly gauged regions of the world.
\end{abstract}

Keywords: TRMM, CMORPH, satellite precipitation, spatial transfer, SWAT. 


\section{Introduction}

Satellite precipitation products have great promise to support hydrologic applications in the third world where ground based monitoring of precipitation is limited. However, there have been some performance issues with these products in terms of comparison with ground precipitation data (see Gottschalck et al. [1]; Ebert et al. [2]; and Tian et al. [3]). Issues include a significant bias that can be over $100 \%$, for example in the US Great Plains, as well as problems with precipitation detection and false alarms (satellite product detecting precipitation when none is sensed by ground based monitoring). A number of approaches have been developed to adjust satellite precipitation mostly focusing on bias correction (Vila et al. [4]). Additionally, Tobin and Bennett [5] developed a method that corrects for bias, lack of precipitation detection, and false alarms.

For the foreseeable future, local ground-based adjustment of satellite precipitation products will be necessary to facilitate their utilization for real world applications. While it is commendable to strive for perfection in rainfall retrievals and algorithm development the reality is that even mature remote sensing platforms still rely on significant ground-based adjustments. For example, the success of the US National Weather Service (NWS) Multi-Sensor Estimator (MPE) and Quantitative Precipitation Estimation (QPE) products are largely based on input from numerous field offices that provide the necessary insights to correct for local bias. This expert local knowledge across the world will be essential as we move into the era of the Global Precipitation Measurement Mission (GPM) to help adjust satellite products over land in order to provide desired input for hydrological applications worldwide.

Consequently, there is a need to determine if adjusted satellite products provide a viable option to quantify precipitation in poorly gauged regions of the world. An additional question is what is the magnitude of uncertainty associated with the adjustment process and its impact on applications such as hydrological simulations? The assumption can be made that uncertainty will increase if the rain gauge utilized in the adjustment process is spatially transferred over a great distance relative to the satellite grid cell that is adjusted. Another basic assumption is that hydrological model results, for example streamflow, should deteriorate if a distal rain gauge is utilized for adjustment. The more interesting question of what is the relationship between spatial transfer distance and streamflow simulation performance is addressed by this study.

This paper examines how streamflow performance based on adjusted satellite precipitation products varies with spatial transfer distance for six moderately large basins from the United States, which span a range of climatic conditions. Satellite precipitation products examined include the TRMM Multi-Satellite Precipitation Analysis (TMPA-RT) and the Climate Prediction Centre (CPC) Morphing Method (CMORPH) both of which have reported issues related to accuracy in well monitored regions such as the United States and Australia (see [1-3]). This study documents the drop-off in streamflow performance as a function of spatial transfer distance associated with the adjustment of these two satellite products. Significantly, this work will provide guidance in terms of how 
a satellite precipitation product can be applied to support the hydrologic modelling of poorly gauged regions of the world.

\section{Study areas and precipitation data description}

Six, moderately large (1971 to $8684 \mathrm{~km}^{2}$ ) basins from CONUS that are located in a diversity of climatic settings were examined in this study, fig. 1. Four basins were from dry climatic regimes (San Pedro, Arizona; Cimarron, Oklahoma; middle Nueces, Texas; mid-Rio Grande, Texas and Mexico) and two basins from a humid climatic setting (Alapaha, Georgia; Upper Tar, North Carolina). Specific details on basin characteristics are provided in Tobin and Bennett [5-8].

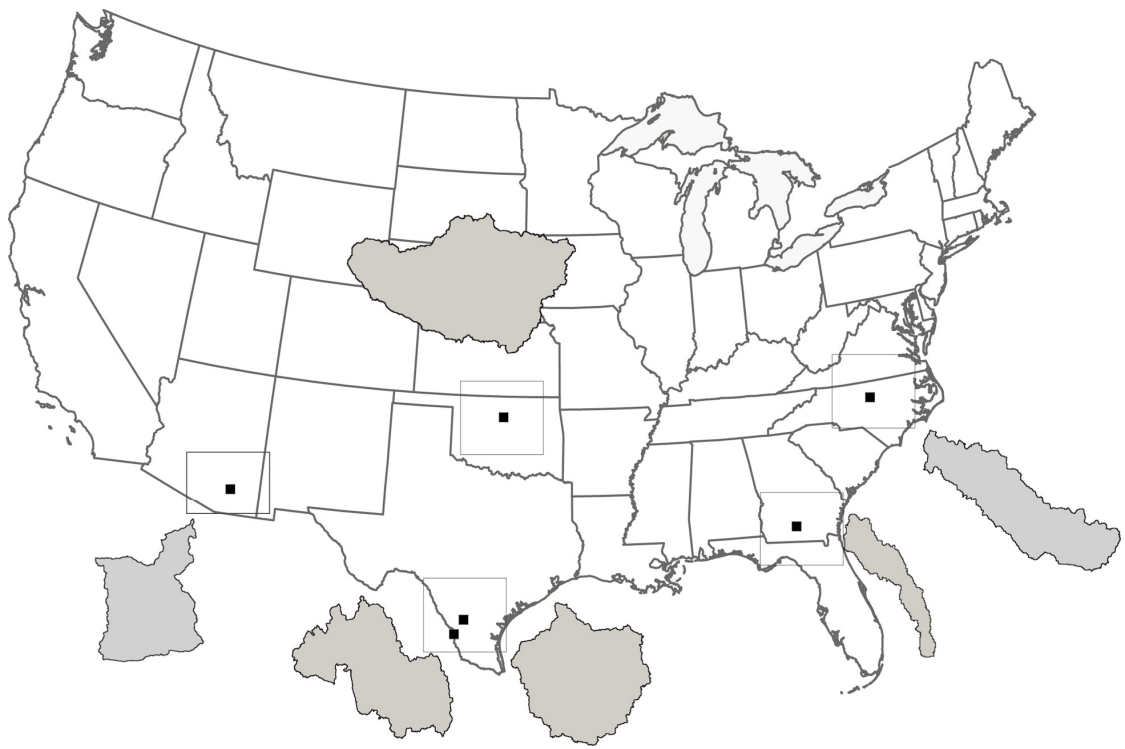

Figure 1: Location of six examined watersheds with up to $5 \times 5^{\circ}$ grid boxes in which precipitation autocorrelation was examined.

This paper utilizes two types of both ground and satellite precipitation products. The two satellite precipitation products that were examined in this study are TMPA-RT and CMORPH. These are considered "real-time" products with a minimal latency on the order of one day or less that can potentially support near real-time hydrological modelling. Both TMPA-RT and CMORPH are pure satellite products, with no ground rain gauge bias correction. TMPA-RT combines passive microwave (PMW) and infrared (IR) precipitation estimates from all available satellites, Huffman et al. [9]. The TMPA-RT utilizes PMWcalibrated IR based rainfall to fill PMW coverage gaps. CMORPH is similar to TMPA-RT in that CMORPH merges satellite precipitation data from both infrared and microwave sensors (Joyce et al. [10]). Unlike TMPA-RT, CMORPH is based on high resolution IR that infers motion of rainfall patterns in 
order to obtain a smooth morphing of PMW rain patterns between PMW snapshots. All precipitation products are aggregated to a daily time interval providing primary input for hydrological validation effort described below.

Ground precipitation data includes NWS MPE, which merges precipitation data from several sources (radar, rain gauge, and passive infrared satellite) and National Weather Service (NWS) daily rain gauge data. The primary data source for the MPE product was hourly NWS Next-Generation Radar (NEXRAD) Stage III data, which covers the area of a US River Forecast Centre. Additional bias corrections were applied using daily NWS rain gauges. Geostationary Operational Environmental Satellite (GOES) passive infrared data was employed to minimize truncation errors in the Stage III processing system associated with a lack of radar coverage in a given area within a river forecast centre zone of responsibility. MPE data is aggregated to a $0.25^{\circ} \times 0.25^{\circ}$ spatial resolution, which corresponds exactly with satellite grid cells and forms the basis for baseline adjustment of satellite products as described below.

All NWS rain gauges with complete or nearly complete (missing fewer than 10 records for period of study, 2003 to 2008) were obtained out to a radius of up to $3.0^{\circ}$ away from the centroid of the six watersheds. The number of rain gauges varies for each watershed (San Pedro, $n=15$; Cimarron, $n=32$; middle Nueces, $\mathrm{n}=25$; mid-Rio Grande, $\mathrm{n}=25$; Alapaha, $\mathrm{n}=21$; Upper Tar, $\mathrm{n}=52$ ). Rain gauge data is used to adjust satellite precipitation data and supports a series of streamflow simulations that evaluate how spatial transfer distance of the ground dataset used to adjust satellite data impacts model streamflow results.

\section{Methodology}

\subsection{Adjustment method}

Ground based adjustment of satellite products is currently needed to support hydrological modelling applications over large regions of the planet. The above statement is especially true for the six watersheds examined in this study where both TMPA-RT and CMORPH have unrealistic values compared with ground based precipitation data, see Tobin and Bennett [5-8].

This study utilizes the precipitation adjustment methodology developed by Tobin and Bennett $[5,6]$, which adjusts satellite products with ground-based precipitation data. The approach is not a simple bias adjustment, but is a threestep process that transforms a satellite product based on a ground-based precipitation data. Ground-based precipitation (MPE, NWS Rain Gauge), which had a detection limit $(0.254 \mathrm{~mm})$, is used to develop a filter eliminating FAR in our adjusted product. Only ground-based values above detection limit were considered positive for precipitation on a given date. For baseline adjustment aggregated MPE values that match exactly the satellite products grid cell were used and to examine spatial transfer distance rain gauge data facilitated the adjustment process. Failure of precipitation detection (POD) was addressed by utilizing ground-based products during these periods in our adjusted product. 
The ultimate result was the transformation of the satellite data into a product that has a perfect equitable threat score $(\mathrm{ETS}=1.00)$.

Correction for bias present in the pure satellite products was facilitated by transformation of the probability distribution frequency (PDF) of satellite product into the PDF of the ground-based precipitation product. The PDF's of both satellite and ground products were calculated based on curve fitting with mixed exponential functions, which is an approach developed by FoufoulaGeorgiou and Lettenmaier [11]; Wilks [12]; and Woolhier and Roldan [13]. Tobin and Bennett [5] provide additional details on the bias adjustment methodology utilized in this study but in brief determination of adjusted satellite product was determined by simultaneously solving satellite product and groundbased precipitation curve fit equations at the exceedence probability based on the satellite product for a given date.

\subsection{Streamflow simulations}

This study compares precipitation products in terms of their ability to support streamflow simulations at the scale of moderately large basins of greater than 1,000 's $\mathrm{km}^{2}$. The semi-distributed hydrologic model selected for this study was the Soil and Water Assessment Tool (SWAT), which is a physically based model with demonstrated global applications and has been validated at the watershed scale through the publication of hundreds of referred papers, see Gassman et al. [14]. Details on model set-up and calibration approach are provided in Tobin and Bennett [5-8].

For each watershed two model sets of SWAT simulations, identical except for daily precipitation input, were executed based on the two precipitation types (Adjusted TMPA-RT, Adjusted CMORPH). Baseline adjustment simulation was completed with MPE aggregated to exactly match the $0.25^{\circ} \times 0.25^{\circ}$ grid cells of the satellite products. Simulations examining spatial transfer distance were completed using NWS rain gauge data to facilitate the adjustment process as describe above. For each simulation a warm-up period of approximately oneyear was utilized to initialize the model. Model results were based on four-year simulations (2004-2007) except for the San Pedro Basin in Arizona where outlet streamflow data availability forced us to establish a simulation period spanning October 1, 2005 to December 31, 2008 for this basin. Two measures were used to quantify the goodness of fit of simulated streamflow relative to observed values and include mass balance error (MBE) and Nash-Sutcliffe efficiency coefficients (NS).

$$
\begin{gathered}
M B E=\left(\frac{\sum_{i=1}^{n}\left(Q_{o b s, i}-Q_{\text {sim }, i}\right)}{\sum_{i=1}^{n}\left(Q_{o b s, i}\right)}\right) X 100 \% \\
N S=1-\left(\frac{\sum_{i=1}^{n}\left(Q_{o b s, i}-Q_{s i m, ~}\right)^{2}}{\sum_{i=1}^{n}\left(Q_{o b s, i}-Q_{o b s, a}\right)^{2}}\right)
\end{gathered}
$$


where $\mathrm{Q}_{\mathrm{obs}, \mathrm{a}}$ is the average observed streamflow. Additionally, $\mathrm{Q}_{\text {sim, } \mathrm{i}}$ and $\mathrm{Q}_{\mathrm{obs}, \mathrm{i}}$ are the simulated and observed surface runoff at the ith observation, respectively and $\mathrm{N}$ is the number of observations. Acceptable simulations have surface runoff that is within 25\% (MSE) of actual surface runoff values with NS values $>0.50$ (Moriasi et al. [15]). Negative NS values indicate that simulated data performs less than if the average of the observed values was utilized when comparing the efficiency of observed and simulated values.

In order to compare numerous simulations between the six basins and two sets of satellite products examined in this study, a relative performance scale (RPS) was established based on MSE and NS values (Table 1). A perfect match between observed and simulated streamflow was equivalent to a relative value of 4.00. A marginal simulation has a RPS value of 1.00. The worst value of the MSE or NS was utilized to assign the RPS value. For example, streamflow with a $\mathrm{MSE}=5 \%$ and a NS $=0.75$ was assigned a relative performance value of 3.00 , which was based on the NS value in this instance that is very good whereas the absolute MSE value is midway between excellent and very good (Table 1).

Table 1: $\quad$ Relative performance scale (RPS).

\begin{tabular}{|c|c|c|c|}
\hline Description & NS & Absolute MSE & RPS Value \\
\hline Perfect & 1.00 & $0 \%$ & 4.00 \\
\hline Very Good & 0.75 & $10 \%$ & 3.00 \\
\hline Good & 0.65 & $15 \%$ & 2.00 \\
\hline Satisfactory & 0.50 & $25 \%$ & 1.00 \\
\hline Mean Simulated & 0.00 & $50 \%$ & 0.00 \\
\hline Poor & -1.00 & $100 \%$ & -1.00 \\
\hline Very Poor & -2.00 & $200 \%$ & -2.00 \\
\hline Extremely Poor & -3.00 & $400 \%$ & -3.00 \\
\hline
\end{tabular}

\subsection{Analysis of precipitation and streamflow data}

Streamflow simulations for each adjusted precipitation type and basin were examined with geostatistical and statistical methods. The geostatistical approach used to evaluate the spatial autocorrelation of bias, probability of detection (POD), and false alarm rate (FAR; defined in [2]) of TMPA-RT and CMORPH products is Ordinary Kriging, which has commonly been used to examine spatial trends in precipitation. Spatial correlograms for precipitation data from each basin were derived and the correlation length, where the auto-correlation dropped to $1 / \mathrm{e}$ (e-folding distance), was then determined. The next step involves generation of the empirical semi-variograms and calculation of the idealized as exponential semi-variogram functions before implementing the Ordinary Kriging procedure as follows:

$$
\gamma(h)=c_{o}+c\left(1-e^{-h / a}\right)
$$


where $\gamma(h)$ is the semi-variance at spatial lag ' $h$ '; $c_{0}$ is the nugget variance (i.e., the minimum variability observed or the 'noise' level at the smallest separating distance equals 0); $\mathrm{c}$ is the sill variance when spatial lag is infinite; and a is the correlation length. Significant auto-correlation was deemed acceptable if a clearly discernable range distinct from the sill was noted in the semi-variogram. Finally, RPS from streamflow results are plotted against spatial transfer distance and linear correlation $\left(\mathrm{r}^{2}\right)$ from the resulting cross-plots were determined.

\section{Results}

Table 2 illustrates the relative proportion of bias, false alarms, and missed precipitation events in the adjusted precipitation product. The contribution of bias forms the dominant attribute within all adjusted satellite products for all basins expect for the San Pedro watershed where correction for false alarms is nearly as important as bias.

Table 2: $\quad$ Misses, false alarms, and bias in adjusted satellite products.

\begin{tabular}{|l|c|c|c|c|}
\hline Basin & Satellite Product & Misses & False Alarms & Bias \\
\hline Alapaha & TMPA-RT & $8-10 \%$ & $4-5 \%$ & $87-90 \%$ \\
\hline Alapaha & CMORPH & $3-4 \%$ & $6-7 \%$ & $89-92 \%$ \\
\hline Upper Tar & TMPA-RT & $7-12 \%$ & $4-6 \%$ & $83-87 \%$ \\
\hline Upper Tar & CMORPH & $5-8 \%$ & $8-11 \%$ & $83-86 \%$ \\
\hline San Pedro & TMPA-RT & $15-19 \%$ & $33-45 \%$ & $37-51 \%$ \\
\hline San Pedro & CMORPH & $7-12 \%$ & $31-38 \%$ & $52-59 \%$ \\
\hline mid-Rio Grande & TMPA-RT & $9-16 \%$ & $7-17 \%$ & $67-83 \%$ \\
\hline mid-Rio Grande & CMORPH & $8-14 \%$ & $15-18 \%$ & $72-77 \%$ \\
\hline Nueces & TMPA-RT & $6-12 \%$ & $7-11 \%$ & $78-85 \%$ \\
\hline Nueces & CMORPH & $4-8 \%$ & $4-17 \%$ & $77-90 \%$ \\
\hline Cimmaron & TMPA-RT & $5-9 \%$ & $5-8 \%$ & $85-88 \%$ \\
\hline Cimmaron & CMORPH & $4-8 \%$ & $11-14 \%$ & $78-83 \%$ \\
\hline
\end{tabular}

Fig. 2 indicates how streamflow simulations based on adjusted TMPA-RT precipitation data vary as a function of spatial transfer distance. Likewise fig. 3 illustrates impact of spatial transfer distance for CMORPH based streamflow simulations. Baseline simulation at a spatial transfer distance of $0^{\circ}$ is based on using MPE data in the adjustment process; whereas all other simulations were based on rain gauge adjustments.

Eleven of the twelve model sets demonstrate a decrease in simulated streamflow response as spatial transfer distance increases. The trend for most model sets was generally linear. For the San Pedro Basin, both TMPA-RT and CMORPH model sets have non-linear relationship can be explained by the complex geography in this region where rain gauges from the dry lowlands provide a better adjustment to satellite data with streamflow RPS values in excess of 3.0. Conversely, especially to the north of the San Pedro Basin rain gauges record much higher precipitation values resulting in an adjusted satellite 

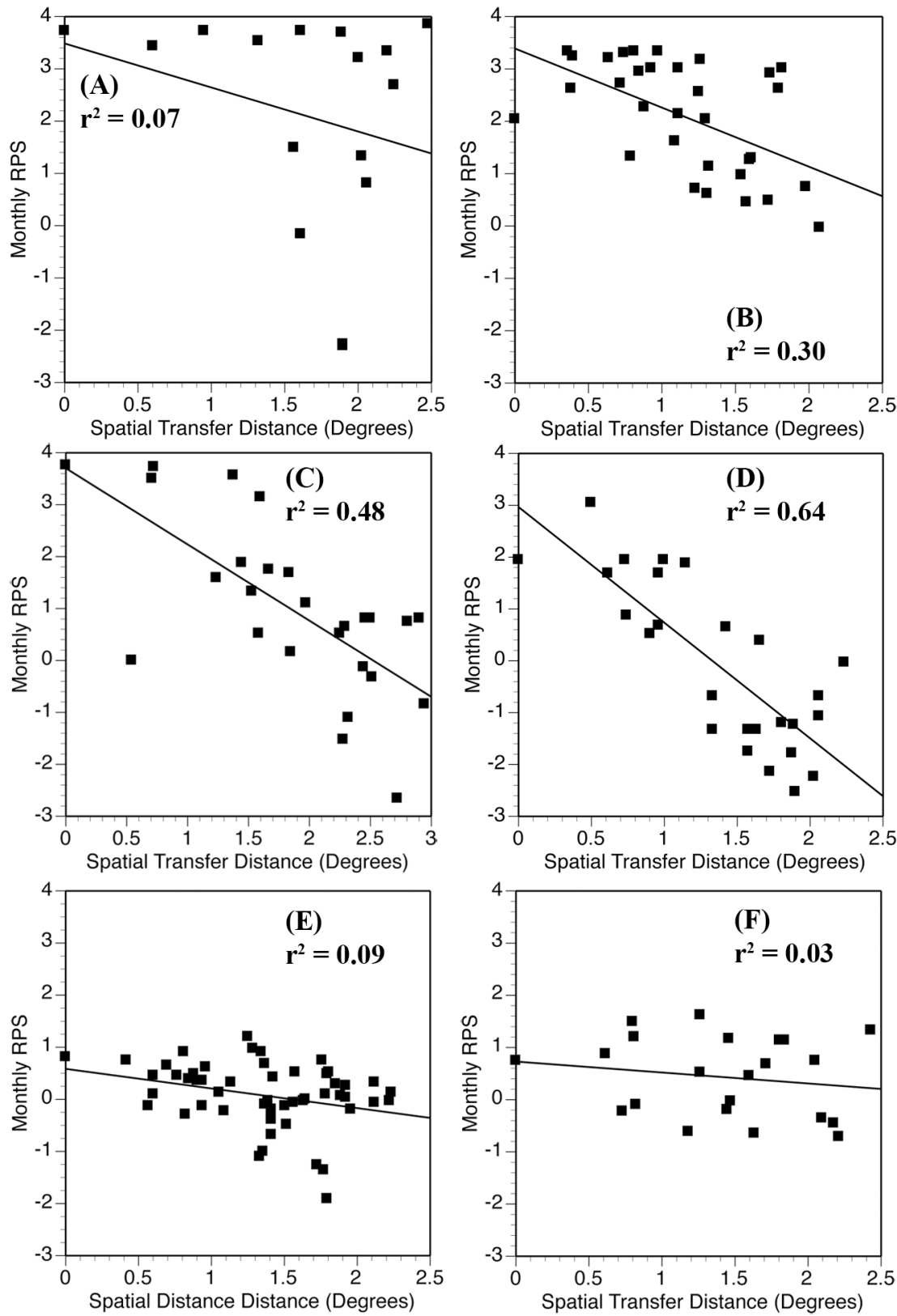

Figure 2: Streamflow simulations based on adjusted TRMM-RT precipitation data. (A) San Pedro Basin, Arizona; (B) Cimarron Basin, Oklahoma; (C) mid-Rio Grande Basin, Texas and Mexico; (D) middle Nueces Basin, Texas; (E) Upper Tar Basin, North Carolina and (F) Alapaha Basin, Georgia. 

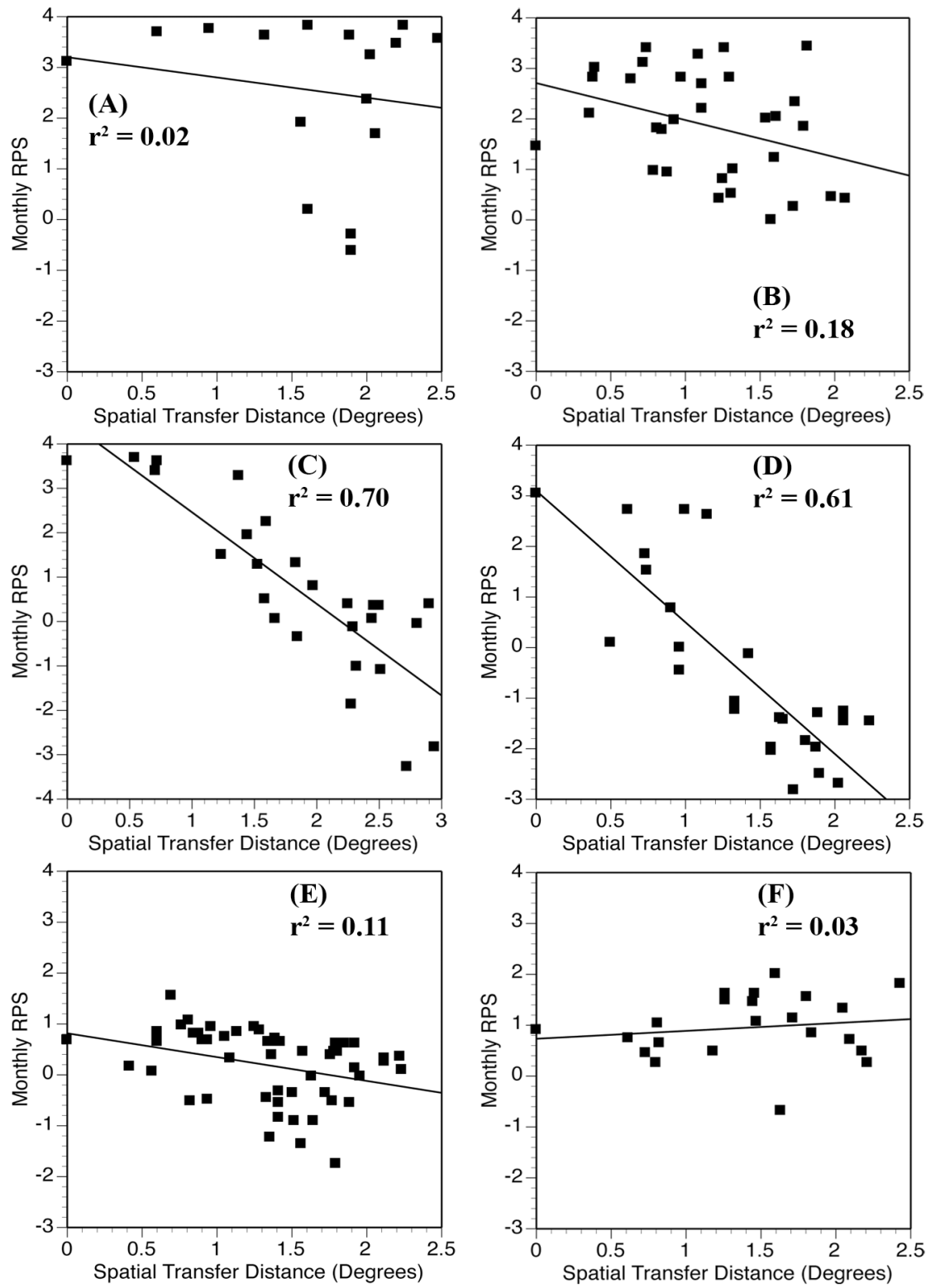

Figure 3: Streamflow simulations based on adjusted CMORPH precipitation data. (A) San Pedro Basin, Arizona; (B) Cimarron Basin, Oklahoma; (C) mid-Rio Grande Basin, Texas and Mexico; (D) middle Nueces Basin, Texas; (E) Upper Tar Basin, North Carolina and (F) Alapaha Basin, Georgia. 
product with unrealistically high precipitation totals that translates into lower streamflow RPS values. The Alapaha CMORPH model set, see fig. 3f, actually has a slight increase in streamflow RPS with increasing spatial transfer distance; although this trend is not statistically significant.

Table 3 illustrates spatial autocorrelation for satellite precipitation performance metrics (Bias, POD, FAR) compared with aggregated MPE that directly corresponds with satellite products over a up to $5 \times 5^{\circ}$ grid surrounding the examined watersheds, fig. 1. In terms of bias, for the Oklahoma, Texas, and Georgia grids e-folding distance for both TMPA-RT and CMORPH range between 1.1 to 1.9 degrees. North Carolina has insignificant autocorrelation for bias. Arizona has insignificant autocorrelation for FAR and bias for the TMPART product whereas CMORPH has e-folding distances that range from 1.4 to 3.2 degrees for bias and FAR.

Table 3: E-folding distance for satellite precipitation performance metrics. E-folding units are based on one degree (1.0).

\begin{tabular}{|c|c|c|c|c|}
\hline Basin & Satellite Product & POD & FAR & Bias \\
\hline Oklahoma & TMPA-RT & 1.4 & 4.2 & 1.9 \\
\hline Oklahoma & CMORPH & 3.2 & 1.9 & 1.1 \\
\hline Texas & TMPA-RT & 2.9 & 2.6 & 1.2 \\
\hline Texas & CMORPH & 3.0 & 2.7 & 1.4 \\
\hline Georgia & TMPA-RT & None & 4.0 & 1.9 \\
\hline Georgia & CMORPH & 1.7 & 2.7 & 1.3 \\
\hline North Carolina & TMPA-RT & 4.4 & 0.6 & None \\
\hline North Carolina & CMORPH & 0.8 & None & None \\
\hline Arizona & TMPA-RT & 1.3 & 0.7 & None \\
\hline Arizona & CMORPH & 2.1 & 1.4 & 3.2 \\
\hline
\end{tabular}

Examination of y-intercept and slope of regression lines from figs. 2 and 3 provide additional insights. The y-intercept is an indication of the RPS value for a simulation at a spatial transfer distance of zero based on the trends in the model sets. The slope indicates the decrease in RPS performance as a function of spatial transfer distance. Fig. 4A provides a plot of y-intercept and slope for the twelve model sets. Two regression lines are indicated, which are similar, with one line including all twelve model sets and the second line omitting model sets that do not have a significant statistical correlation. Both regression lines are statistically significant determined with a one-tailed t-statistic at a $p=0.05$. These regression lines indicate that as the y-intercept decreases the slope (or the decrease of RPS per degree of latitude/longitude) also decreases.

\section{Discussion and significance}

Figure 4B provides an answer to the question of how streamflow performance deteriorates as a function of spatial transfer distance for the adjusting precipitation data set. For a streamflow simulation to be acceptable they must have a RPS value 
of 1.00. The higher the RPS value of the baseline simulation where ground based precipitation data exactly matches satellite products the longer the spatial transfer distance is permissible. The preliminary results presented in this paper indicate that for baseline simulations that are good (RPS $=2.00$ ), very good (RPS $=3.00$ ), and excellent $(\mathrm{RPS}=4.00)$ that tolerable spatial transfer distances are $0.9 \pm 0.3^{\circ}$, $1.3 \pm 0.4^{\circ}$, and $1.5 \pm 0.5^{\circ}$, respectively. While these precise values may not apply to every basin, this study strongly implies that ground-based precipitation data can be utilized over spatial transfer distances comparable to e-folding distance of satellite precipitation performance metrics, most notably bias and FAR. As such this contribution provides guidance for how satellite precipitation products can be adapted for local applications in poorly monitored regions of the world.
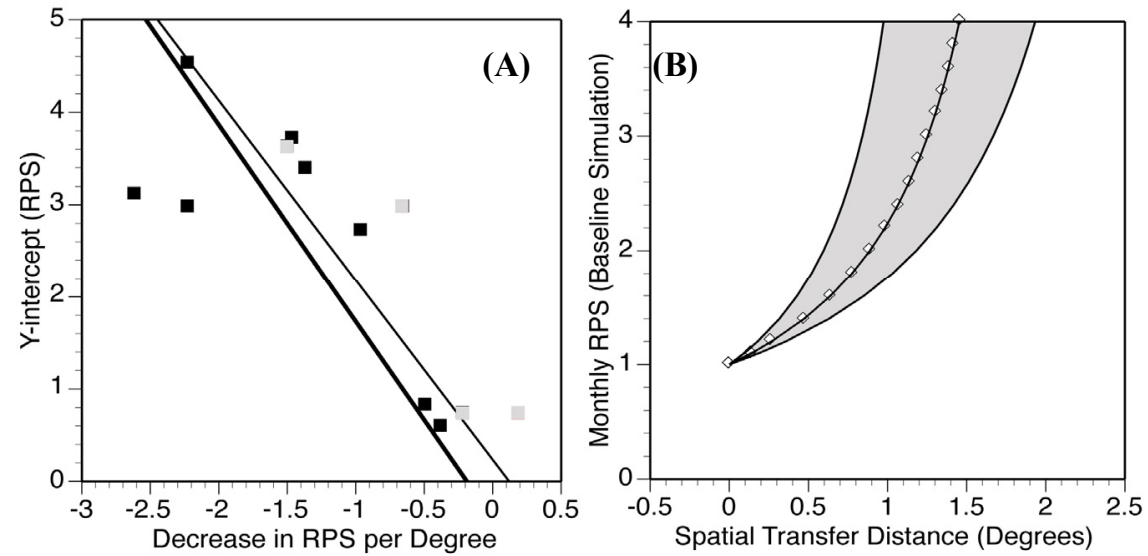

Figure 4: (A) Y-intercept of regression lines against decrease in RPS per degree from figs. 2 and 3. Gray symbols represent regression lines (from figs. 2 and 3 ) that do not have statistically significant correlations. Thin regression line includes all sets of simulations and thick line omits simulation sets that do not have a statistically significant correlation. (B) Relationships between monthly RPS of baseline simulation where ground based precipitation data exactly matches satellite products and spatial transfer distance in degrees. Envelop for data set is based on two standard deviations of the standard error.

\section{References}

[1] Gottschalck, J, Meng, J., Rodell, M. \& Houser, P. Analysis of multiple precipitation products and preliminary assessment of their impact on Global Land Data Assimilation System Land Surface States. Journal of Hydrometeorology. 6, pp. 573-598, 2004.

[2] Ebert, E. E., Janowisk, J. E. \& Kidd, C.. Comparison of near-real-time precipitation estimates from satellite observations. Bulletin of American Meteorological Society. 88, pp. 47-64, 2007. 
[3] Tian Y., Peters-Lidard, C. D., Choudhury, B. J. \& Garcia, M., Multitemporal analysis of TRMM-based satellite precipitation products for land data assimilation applications. Journal of Hydrometeorology, 8, pp. 1165$1183,2007$.

[4] Vila D. A., De Goncalves, L. G. G., Toll, D. L. \& Rozante, J. R. Statistical evaluation of combined daily gauge observations and rainfall satellite estimates over continental South America. Journal of Hydrometeorology, 10, pp. 533-543, 2009.

[5] Tobin, K.J. \& Bennett, M.E., Adjusting satellite precipitation data to facilitate near real-time hydrologic modeling. Journal of Hydrometerology, 11, pp. 967-979, 2010.

[6] Tobin, K.J. \& Bennett, M.E., Validation of satellite precipitation adjustment methodology from six basins in CONUS. Journal of the American Water Resources Association, in review.

[7] Tobin, K.J. \& Bennett, M.E., Comparison of NWS rain gauge, NEXRAD Stage III, and TRMM 3B42 precipitation estimates for hydrological modelling: Middle Nueces Watershed, South Texas. Journal of the American Water Resources Association, 47(1), pp. 254-271, 2009.

[8] Tobin, K.J. \& Bennett, M.E., Remotely sensed satellite precipitation and soil moisture estimates to support hydrological modelling in a large basin from Oklahoma, International Journal of Water Resources and Environmental Management, 1, pp. 1-16, 2010.

[9] Huffman, G. J., Adler, R. F., Bolvin, D. T., Gu, G., Nelkin, E. J., Bowman, K., Stocker, E. F. \& Wolff, D., The TRMM Multi-satellite Precipitation Analysis (TMPA): quasi-global, multi-year, combined-sensor precipitation estimates at fine scales. Journal of Hydrometeorology, 8, pp. 38-55, 2007.

[10] Joyce R. L., Janowiak, J. E.,. Arkin, P. A \& Xie, P. CMORPH: A method that produces global precipitation estimates from passive microwave and infrared data at high spatial and temporal resolution. Journal of Hydrometeorology, 5, pp. 487-503, 2004.

[11] Foufoula-Georgiou, E. \& Lettenmaier, D. P., A Markov renewal model for rainfall occurrences, Water Resources Research, 23, pp. 875-884, 1987.

[12] Wilks, D. S. Statistical Methods in the Atmospheric Sciences. 2nd Edition, Elsevier: Amsterdam, pp. 627, 2006.

[13] Woolhier, D. A. \& Roldan, J., Stochastic daily precipitation models, 2. A comparison of distribution and amounts. Water Resources Research, 18, pp. 1461-1468, 1982.

[14] Gassman, P. W., Reyes, M. R., Green, C. H. \& Arnold, J. G., The Soil and Water Assessment Tool: historical development, applications, and future research directions, Transactions of the ASABE. 50, pp. 1211-1250, 2007.

[15] Moriasi, D. N., Arnold, J. G., Van Liew, M. W., Bingner, R. L., Harmel, R. D. \& T. L. Veith, Model evaluation guidelines for systematic quantification of accuracy in watershed simulations. Transactions of the ASABE. 50, pp. 885-900, 2007. 